\title{
Structure Optimization and Numerical Analysis of Cement Concrete Overlay of Some Secondary Road overlay
}

\author{
$\mathrm{Li} \mathrm{Moshu}^{1, \mathrm{a}}$, Yang Jianming ${ }^{1, \mathrm{~b}}$ and $\mathrm{He} \mathrm{Chao}^{1, \mathrm{c}}$ \\ ${ }^{1}$ Institute of Urban Construction, University of South China, Hengyang, 421001, China. \\ alimoshu@163.com, byangjianming@126.com, chechao@163.com
}

Keywords: Cement concrete overlay, Plate width divided, Vehicle load and temperature stress, Finite element analysis

\begin{abstract}
According to disease investigation of cement concrete overlay of some secondary road in Hunan province, analysis model is built by ABAQUS finite element software. Research shows that the mechanical properties of cement concrete overlay of scheme B, C, D is better than scheme A . And scheme $C(3.5 m+4 m+3.5 m)$ is the recommended scheme, with its vehicle load and temperature stress of cement concrete pavement the smallest, longer fatigue life. Reference is proposed for design of secondary highway cement concrete pavement overlay.
\end{abstract}

\section{Introduction}

When vehicles are overloaded or pavements are closed to their service lives, there will appear edge failure, corner breakage, slab damage, faulting, raphe burst, pumping and other diseases in the pavements of the cement concretes. In order to recover functions of old cement concretes, usually, the cement concrete surfaces or asphalt concrete surfaces are overlaid. The cases of asphalt concrete overlays are more than the cases of cement concrete overlays. With different forms of overlays, cement concrete overlays can be divided into combining overlays, separate overlays and direct overlays. Sometimes because of the construction, which is more convenient to construct simultaneously on the secondary road traffic lines and surface layer of hard shoulder. So, we usually adopt two plates'design of overlay, which causes too wide panel of cement concrete and influences the service life of cement concrete. What's more, during the process of reconstructing secondary road, the curve radius and inside roadbed may widen because of the linear optimization. At the same time, with the possibility of partial differential settlement, they both influence the quality of cement concrete overlay or lead to certain diseases. This paper aims to search for suitable construction of cement concrete overlay and give a reference to the design of old cement concrete overlay on the basis of researching the cement concrete overlay and diseases of G322 road( Hengnan SantangQidong Baidi city section).

\section{Survey of Old Cement Concrete Overlay and Diseases}

According to the currrent specifications of plate sizes of highway concretes, plate widths of concretes should be 3.0-4.5m, with its length of 4.0-6.0m, length-width ratio no more than 1.35 and plane area no more than $25 \mathrm{~m}$. The cement concrete pavement of G322 road( Hengnan SantangQidong Baidi city section) adopts the cement concrete overlay, with its width of $11 \mathrm{~m}$, by the way of firstly paving a layer of insulation felt, then overlaying 30m C35 cement concrete surface layer. For the roadbed, it remains $12 \mathrm{~m}$ as its original roadbed. At the transverse direction, the cement concrete overlay is constructed by two and three plates. Namely, they are scheme $A(5.5 \mathrm{~m}+5.5 \mathrm{~m}=11 \mathrm{~m})$, and scheme $\mathrm{B}(4.0 \mathrm{~m}+3.0 \mathrm{~m}+4.0 \mathrm{~m}=11 \mathrm{~m})$ as the cement concrete overlays. Both widths of cement concretes are $5 \mathrm{~m}$, but for scheme $\mathrm{B}$, in the middle of its partial section, the width is $3 \mathrm{~m}$ and the length is $10 \mathrm{~m}$. Due to the route linear optimization in the partial curved section, the curve radius and inside roadbed in the curved section may widen.

According to the survey, differnt overlay schemes of cement concrete bring about diseases in different degrees. Two plates' cement concrete overlay appears longitudinal cracks around 
$2.0 \mathrm{~m}-2.5 \mathrm{~m}$ away from the pavement edges, especially in the curved section of highways, as shown in figure 1a. In the three plates'cement concrete overlay, the conventional cement concrete plates of $5 \mathrm{~m}$ length are almost intact, while the cement concrete plates of $10 \mathrm{~m}$ length in the middle partial pavement along the long central section appear cracks in the transverse direction, as shown in figure $1 b$.

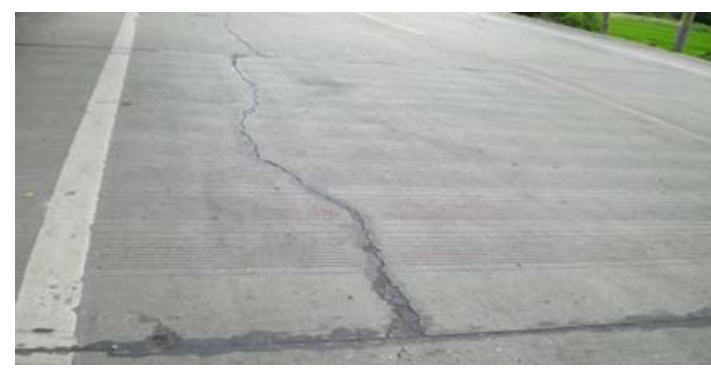

a.Longitudinal cracks

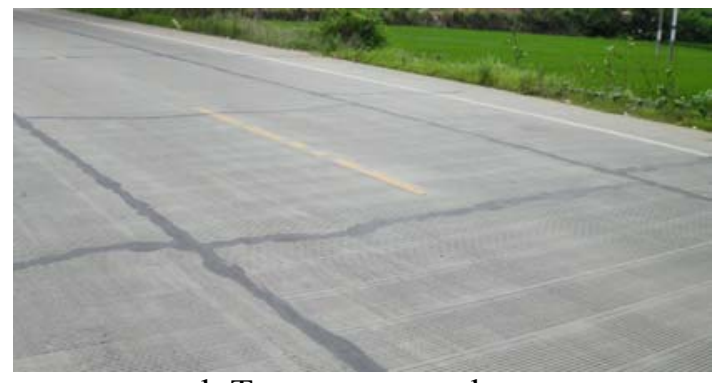

b.Transverse cracks

Fig.1 Disease chart of cement concrete overlay

\section{Calculation Model and Parameters}

When old cement concrete pavement of G322 road is overlaid by cement concretes, the original overlay design schemes include scheme A and scheme B.The longitudinal cracks of scheme A are related to differential settlement. The transverse cracks of scheme B in the partial section of $10 \mathrm{~m}$ length mainly result from the over length of plate which leads to the temperature stress. Scheme B's usability is better than scheme B and scheme B's service life is longer. But scheme B is not the best, its wheel tracks being too close to the plate edge in the process of vehicles'driving, which may cause premature rupture of cement concrete surface layers. According to those, scheme C and D are the comparisons, and partition plate width of scheme as shown in table 1.

Table 1 Partition plate width of the scheme

\begin{tabular}{cccc}
\hline Scheme A & Scheme B & Scheme C & Scheme D \\
\hline $5.5 \mathrm{~m}+5.5 \mathrm{~m}$ & $4.0 \mathrm{~m}+3.0 \mathrm{~m}+4.0 \mathrm{~m}$ & $3.5 \mathrm{~m}+4.0 \mathrm{~m}+3.5 \mathrm{~m}$ & $3.0 \mathrm{~m}+5.0 \mathrm{~m}+3.0 \mathrm{~m}$ \\
\hline
\end{tabular}

The layer structure of this road pavement is : $30 \mathrm{~cm} \mathrm{C30} \mathrm{cement} \mathrm{overlay+} \mathrm{asphalt} \mathrm{felt}+24 \mathrm{~cm} \mathrm{C} 30$ old cement concrete pavement $+20 \mathrm{~cm}$ cement stabilied sand gravel $+16 \mathrm{~cm}$ graded crushed stone, which is overlaid by separated paving form. In this model, the height of the roadbed is $1.5 \mathrm{~m}$, the grade of side slope is 1:1.5.Supposing that all layer structures are made of elastic materials, then the main parameters of all layer structures are shown as table 2. The load transfer between pull rods of the cement concrete overlay's plates, is simulated by shearing the butt joints of the spring unit, while the rigidity $\mathrm{q}$ is figured out by Friberg Theory.

Table 2 The pavement structure and the main parameters

\begin{tabular}{cccc}
\hline Structure layer & Thickness $(\mathrm{m})$ & Elastic modulus(MPa) & Poisson's ratio \\
\hline concrete overlay & 0.30 & 31500 & 0.15 \\
Old concrete pavement & 0.24 & 30000 & 0.15 \\
cement stabilized sand gravel & 0.20 & 1400 & 0.20 \\
graded broken stone & 0.16 & 300 & 0.30 \\
soil matrix & 1.50 & 50 & 0.30 \\
\hline
\end{tabular}

\section{Calculation Analysis}

Vehicle Load. In the finite element calculation, the vehicle load adopts Bzz-100 standard axle load in the Design Specifications (JTGD40-2011)of Road Cement Concrete Pavement.When vehicles drive on the pavements, away from the pavements about $0.75 \mathrm{~m}-1.25 \mathrm{~m}$, the times of vehicle 
loads ,which are the most, take up $60 \%$ times of total axle loads. In the model, the load position happens when vehicles driving in a normal state and in the worst loading position. According to the distribution frequency of former wheel tracks, supposing that the position of vehicles driving in a normal state is the place where the tire being $1 \mathrm{~m}$ away from the central line of the road, and the worst loading position lying in the longitudinal middle part in the pavement edge, then the calculation result is shown in table 3.

Table 3 The maximum bending stress value of plate bottom of cement concrete overlay of each scheme in vehicle load

\begin{tabular}{cccccc}
\hline Load position & $\begin{array}{c}\text { Overlay } \\
\text { scheme }\end{array}$ & $\begin{array}{c}\text { Standard axle } \\
\text { load }\end{array}$ & $\begin{array}{c}\text { Overloaded } \\
20 \%\end{array}$ & $\begin{array}{c}\text { Overloaded } \\
50 \%\end{array}$ & $\begin{array}{c}\text { Overloaded } \\
100 \%\end{array}$ \\
\hline $\begin{array}{c}\text { The maximum } \\
\text { bending stress value }\end{array}$ & $\mathrm{A}$ & 0.479 & 0.574 & 0.718 & 0.957 \\
in a normal driving & $\mathrm{B}$ & 0.524 & 0.629 & 0.786 & 1.048 \\
state(MPa) & $\mathrm{C}$ & 0.482 & 0.578 & 0.723 & 0.964 \\
\hline The maximum & $\mathrm{D}$ & 0.480 & 0.576 & 0.721 & 0.960 \\
bending stress value & $\mathrm{A}$ & 0.879 & 1.055 & 1.319 & 1.759 \\
in a worst position & $\mathrm{B}$ & 0.880 & 1.056 & 1.321 & 1.76 \\
$\quad \mathrm{MPa})$ & $\mathrm{C}$ & 0.881 & 1.057 & 1.322 & 1.762 \\
& $\mathrm{D}$ & 0.882 & 1.058 & 1.323 & 1.764 \\
\hline
\end{tabular}

From table 3 we know that, when vehicles driving in a normal state, the vehicle loads of scheme A, C, D cause less bending stress values, but scheme B, with its longitudinal joint nearing the wheel tracks, the reciprocal action of the vehicles has some influence on the joint, easily bringing out the joint diseases, which leads to rain infiltrating into the grass-roots levels and the service life of the pavements shortening. The position of the longitudinal joint of overlay scheme $\mathrm{C}$ and $\mathrm{D}$ are away from the wheel tracks as the vehicle driving for more than $0.5 \mathrm{~m}$, which greatly reduces the cement concrete bending stress.

When the vehicle load in the worst position, cement concrete's maximum bending stress values of all plans are almost the same. The wider cement concrete plate in the outermost layer of the cement concrete overlay, the smaller bending stress of the cement concrete will be. But the differences between all plans are small, which can be almostly ignored. So we analyze the vehicle loads of cement concretes in its worst position, we can consider the maximum bending stress values of cement concrete plates in different widths of the vehicle load are the same.

Temperature stress. When cement concrete pavement in the positive temperature gradient, its temperature warping stress is bigger than in its negative temperature gradient. Therefore, the temperature load in the model is calculated with its positive temperature gradient, supposing that temperature gradient of the concrete pavement is $88^{\circ} \mathrm{C} / \mathrm{m}$, with the coeffcient of linear expansion of the concrete of $1.0 * 10^{-5} /{ }^{\circ} \mathrm{C}$, the density of $\rho=2400 \mathrm{~kg} / \mathrm{m}^{3}$, the heat conductivity coefficient of $1.5 \mathrm{~W} /(\mathrm{m} \cdot \mathrm{K})$, the specific heat capacity of $0.945 \mathrm{KJ} / \mathrm{Kg}^{\circ} \mathrm{C}$. Through the calculation by finite element, the maximum temperature warping stresses of $5 \mathrm{~m}$ single block of cement concrete overlay with different widths are shown in table 4.

Table 4 Temperature stress value of a single block of cement concrete overlay

\begin{tabular}{cccc}
\hline $\begin{array}{l}\text { The width of the } \\
\text { cement concrete } \\
\text { overlay }(\mathrm{m})\end{array}$ & $\begin{array}{c}\text { The maximum } \\
\text { temperature stress } \\
(\mathrm{MPa})\end{array}$ & $\begin{array}{c}\text { The width of the } \\
\text { cement concrete } \\
\text { overlay }(\mathrm{m})\end{array}$ & $\begin{array}{c}\text { The maximum } \\
\text { temperature stress } \\
(\mathrm{MPa})\end{array}$ \\
\hline $2.0 \mathrm{~m}$ & 1.122 & $4.0 \mathrm{~m}$ & 1.256 \\
$2.5 \mathrm{~m}$ & 1.140 & $4.5 \mathrm{~m}$ & 1.314 \\
$3.0 \mathrm{~m}$ & 1.169 & $5.0 \mathrm{~m}$ & 1.409 \\
$3.5 \mathrm{~m}$ & 1.209 & $5.5 \mathrm{~m}$ & 1.595 \\
\hline
\end{tabular}

From table 4 we know that, when the width of cement concrete plate is less than $4 \mathrm{~m}$, the temperature stress is small. When the width of cement concrete is $2 \mathrm{~m}$ to $4 \mathrm{~m}$, its maximum temperature warping stresses is $1.122 \mathrm{MPa}-1.256 \mathrm{MPa}$. The stress growth rate increases smoothly, 
with the width of cement concrete plate growing each $0.5 \mathrm{~m}$, the temperature warping stress increasing about $2 \%-3 \%$. When the width of cement concrete overlay is $4 \mathrm{~m}-5 \mathrm{~m}$, the stress growth rate begins to increase, width growing each $0.5 \mathrm{~m}$ will increase about $5 \%-7 \%$. When the width of cement concrete overlay is more than $5 \mathrm{~m}$, the stress increses sharply, from $5 \mathrm{~m}-5.5 \mathrm{~m}$, with the width of cement concrete plate growing each $0.5 \mathrm{~m}$, the temperature warping stress increasing $13 \%$. In the design of cement concrete pavement, the width of cement concrete plate is suitable for about $4 \mathrm{~m}$. In that, it not only guarantees the intergrity of the pavement, but also make the temperature warping stress in the lowest level. With the with of a single block of cement concrete overlay increased, the variation tendency of its maximum temperature warping stress is shown in figure 2.

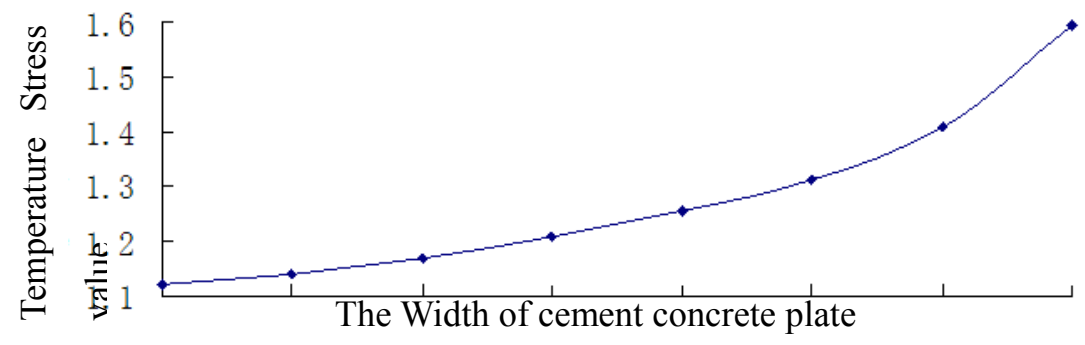

Fig. 2 temperature stress value map of different width of cement concrete overlay

The orginal scheme A of cement concrete overlay is made up of two plates cement concrete, its temperature stress is relatively high.The sizes of scheme $\mathrm{B}$ and C's cement concrete plates both are $3 \mathrm{~m}-4 \mathrm{~m}$, their biggest temperature stresses are almost the same. But in the design of pavements, the calculated stress is the vehicle load of the cement concrete plate in the critical load position and the temperature load. The width of outside cement concrete plate of scheme $\mathrm{C}$ is smaller than scheme B's. The dicrease of temperature stress of scheme C takes the advantage. Scheme D is made up of two $3 \mathrm{~m}$ and one $5 \mathrm{~m}$ wide cement concrete plates. Comparing to scheme $\mathrm{B}$ and $\mathrm{C}$, its width in the middle of the cement concrete reaches $5 \mathrm{~m}$, thus its temperature stress grows rapidly. Its temperature stress rises to $1.409 \mathrm{MPa}$, which is $12 \%$ bigger than the maximum temperature warping stress of scheme B's cement concrete plate.

Analysis of Differential Settlement Elements of Pavements. In the process of roads' reconstruction, some linear variation of partial routine leads to broadening the curve radius and inside roadbed in the curved section. So there may still exist the influence of partial differential settlement. In the simulation of differential settlement in the pavements, the model adds a displacement boundary condition at the bottom of the embarkment boundary. Supposing that the settlement is little for the old roadbed in the boundary of the broaden roadbed, its settlement begining to increse. At the pavement edge, the settlement grows to the maximum value. The wider the roadbed, the more of the curve variation of differential settlement and maximum settlement will be. Different broaden widths of pavements have almost the same maximum settlement position and settlement variation curve. In order to calculate more conveniently, we usually simplify the variation curve of differential settlement of pavements into parabola or sinusoid and cosinusoid. Lots of surveys show that this simplification is practical, which relatively approaches the realities of subgrade deformations. When differential settlement happens in the pavements, this paper adopts the way of loading a boundary condition at the vertical displacement of the bottom of the roadbed. If the old partial pavements of traffic lines have no differential settlement, the maximum settlement position being the pavement edge, then we adopts the cosinusoid to describe the differential settlement in the broaden roadbed which is under the road shoulder. The expression is the following,

$$
\delta=\delta_{\max } \cos (\pi x / 2 B)
$$

$\delta_{\max }$ is the maximum settlement, B is the width of broaden roadbed. The main factor which influences the structure of pavement is the maximum settlement $\delta_{\max }$ of the roadbed and the length $\mathrm{L}$ of the differential settlement of the roadbed. In the broaden roadbed, the characteristic length $\mathrm{L}$ is the distance from the boundary of new and old roadbeds to the pavement edge. At the same, we definite and calculate the ratio of alter gradient of settlement $\Delta i$. The results are shown in table 5 . 
Table 5 the maximum stress value of different overlay scheme

\begin{tabular}{cccc}
\hline $\begin{array}{c}\text { The ratio of settlement and } \\
\text { alter gradient }\end{array}$ & $0.1 \%$ & $0.2 \%$ & $0.3 \%$ \\
\hline Overlay scheme A & 0.389 & 0.826 & 1.244 \\
Overlay scheme B & 0.365 & 0.771 & 1.159 \\
Overlay scheme C & 0.346 & 0.722 & 1.072 \\
Overlay scheme D & 0.296 & 0.601 & 0.900 \\
\hline
\end{tabular}

The overlay scheme of two plates, whose cement concrete overlay stress is bigger, scheme A's stress is $6.6 \%$ more than scheme B's. The arrangement form of three plates'cement concrete is better. When differential settlement alter gradient ratio of the broaden roadbed increases from $0.1 \%$ to $0.3 \%$, from the table, we can see the cement concrete plate's width of the outside overlay becomes small. With the settlement growing, the increase of the stress becomes small. When the differential settlement alter gradient ratio is $0.1 \%$, the maximum stresses of overlay scheme $\mathrm{C}$ and $\mathrm{D}$ are respectively $0.346 \mathrm{MPa}$ and $0.296 \mathrm{MPa}$. Comparing to scheme $\mathrm{B}$ of its orginal pavement, the stress of scheme $\mathrm{C}$ decreases $5.2 \%$, and the stress of scheme $\mathrm{D}$ decreasing $18.9 \%$. With the growth of differential settlement alter gradient ratio, when the settlement alter gradient ratio is $0.3 \%$, comparing with the original scheme $\mathrm{B}$, the the maximum stresses of scheme $\mathrm{C}$ and $\mathrm{D}$ respectively reduce for $7.5 \%$ and $22.3 \%$.

\section{The Selection of Overlay Scheme}

Vehicle Load StressWhen vehicles drive in a normal state in the traffic line, comparing with the orginal scheme $\mathrm{b}$, caused by the vehicle load, the bending stresses of scheme $\mathrm{c}$ and $\mathrm{d}$ respectively reduce $8.02 \%$ and $8.4 \%$. When the vehicle in its worst position, we can regard the bending stresses of different broad cement concretes in the same value.

Temperature Load StressThe cement concrete two plates'overlay form of scheme A is too wide, its temperature stress of scheme $\mathrm{A}$ is the biggest among the four schemes. The cement concrete plate's widths of scheme B and C are both $3-4 \mathrm{~m}$ in a average value and their temperature stresses are almost the same. But in the calculation of service life of cement concrete pavements, it is calculated by the maximum bending stress in the critical load position of the cement concrete when the vehicle in the pavement edge. The maximum temperature stress of both side cement concrete plates of scheme $\mathrm{C}$ is $3 \%$ less than scheme B's. In the overlay scheme $\mathrm{D}$, with its wider cement concrete plate, its temperature stress is $12 \%$ higher than the original scheme B's.

The Influence of Differential Settlement of PavementThe narrower the width of cement concrete overlay in its two sides, the differential settlement in its road shoulder section has less added stress of the cement concrete. Comparing with the original scheme B, scheme C's overlay stress from its differential settlement reduces $5 \%$, scheme D reducing about $19 \%$.

Selection of Overlay SchemeThe cement concrete arrangement form of scheme $d$ has good adaptability on its differential settlement of the broaden roadbed, but comparing to scheme b, its temperature stress increases $12 \%$. According to the current specification of cement concrete design, we usually consider the vehicle load and temperature load in the critical load position of the cement concrete, so advantages of plan D may not be greater than scheme B's.

When in the normal driving state, scheme c's vehicle load stress, the added stress caused by road differential settlement, and its temperature stress of cement concrete plates in its two sides are all less than scheme b's. Namely, when vehicles driving in a normal state, the cement concrete bending stress of scheme c reduces $8 \%$ than scheme b's, with its temperature stress in its outside cement concrete reducing 3\%. So scheme c has better adaptability on differential deformation of the roadbed. According to the current specification, we adopt the cement concrete fatigue formula to have an calculation. In the same thickness of cement concretes, overlay's fatigue life increases more than $15 \%$, so scheme $\mathrm{c}$ has good performance index. Scheme c with $3.5 m+4 m+3.5 m$ is the best choice. 


\section{Conclusion}

When the secondary road pavement is relatively wide, using the two plates' cement concrete's overlay scheme, the layer of cement concrete will break quickly. So we adopt the three plates' cement concrete or separately pave the hard shoulder and pull rod. When we adopt the scheme of three plates' cement concrete, the longitudinal joint should be away from the concentration domain of the vehicle wheel tracks for more than $0.5 \mathrm{~m}$. Thus in that way, the vehicle load has little effect on the joint, which improves the overal integrity of the pavements.

When we adopt the three plates' plan, the width of cement concrete overlay should be about $4 \mathrm{~m}$. The wider cement concrete plate should be put in the middle of the pavement, while for the narrower cement concrete plate should be put in the outside, so that it can reduce the vehicle and temperature's combination stress and the influence on broaden pavement's differential settlement.

G322 road cement concrete overlay should adopt the scheme c, that is the plate construction of $3.5 \mathrm{~m}+4 \mathrm{~m}+3.5 \mathrm{~m}$. In the same thickness of the cement concrete pavement, when the vehicles driving in a normal state, the cement concrete overlay stress can reduce $8 \%$ and the temperature stress of outside cement concrete palte can reduce 3\%. At the same time, the overlay has better deformation adoptability to the broaden roadbed, and the fatigue life of the overlay can increase more than $15 \%$.

\section{Reference}

[1] Fu zhi, Jin zhiqiang. Cement Concrete Pavement Surface Construction and Maintenance and Repair Methods[M]. Beijing: China Communications Press, 2004.

[2]Technical Specification For Detecting AND. Specifications of Cement Concrete Pavement Design for Highway(JTGD40-2011)[S].Beijing: China Communications Press, 2001.

[3]He chao. Disease Analysis and Numberical Study of two Stage Highway of Paving Cement Concrete Pavement [D]. University of South China, 2014.

[4]Zhou zhengfeng, Lin jianming. Finite Element Model of Airport Rigid Pavement Structure Based on ABAQUS[J]. Journal of Traffic and Transportation Engineering,2009,9 (3) .39-44.

[5]Zhou zhengfeng, Lin jianming, Yuan jie.Finite Element Analysis of the Load Transferr Efficiency of Joints of Airport Rigid Pavement[J]. China Civil Engineering Journal,2009,42(2). 112-118.

[6]Lu dingzhong, Chen jiaju.Subgrade and Pavement Construction[M]. Shanghai: Tongji University Press, 2009.

[7]Li chunming.Applicability Analysis of Existing Widening Pavement Structure[J].North Traffic.2011, (11) .31-33.

[8]Ying ronghua, He wanglin, Jiang pu. Study on the Differential Settlement of Old Widened Road with FEM[J].Highways and Automative Applications,2005,(4).79-81.

[9]Zhou wen. Analysis Influences of Strength Inhomogeneity of New and Old Subgrade for Widening Pavement Structure.[J].Highway Engineering,2009,5(34).67-74. 